\title{
Medical and socio-demographic determinants of depressive disorders in diabetic patients
}

\author{
Magdalena Florek-Łuszczki ${ }^{1, A, C-F \oplus}$, Piotr Choina ${ }^{1, B, F \oplus}$, Ewa Kostrzewa-Zabłocka ${ }^{2, B, F}{ }^{\text {, }}$ \\ Lech Panasiuk ${ }^{2, \mathrm{~B}, \mathrm{~F} \oplus}$, Piotr Dziemidok ${ }^{2, \mathrm{~B}, \mathrm{E}-\mathrm{F} \oplus}$ \\ ${ }^{1}$ Department of Medical Anthropology, Institute of Rural Health, Lublin, Poland \\ ${ }^{2}$ Institute of Rural Health, Lublin, Poland \\ A - Research concept and design, B - Collection and/or assembly of data, C - Data analysis and interpretation, \\ $D$ - Writing the article, E - Critical revision of the article, F - Final approval of article
}

Florek-Łuszczki M, Choina P, Kostrzewa-Zabłocka E, Panasiuk L, Dziemidok P. Medical and socio-demographic determinants of depressive disorders in diabetic patients. Ann Agric Environ Med. 2020; 27(2): 255-259. doi: 10.26444/aaem/118529

\begin{abstract}
Introduction. Diabetes is a civilisation disease creating a serious challenge for public health. In Poland, approximately 2 million people suffer from diabetes, of which about $25 \%$ are unaware of their illness. A considerable part of persons with diabetes experience complications related with the disease.

Objective. The aim of the study was to determine the relationship between elements of the state of health and sociodemographic characteristics of diabetic patients treated in the Diabetes Clinic at the Institute of Rural Health (IMW) in Lublin, eastern Poland, and the occurrence of depressive symptoms in these patients.

Materials and method. The study was conducted in 2017-2018 among patients treated in the Diabetes Clinic at the Institute of Rural Health in Lublin, by the method of a diagnostic survey using the Beck's Depression Inventory and an author-constructed questionnaire, as well as data from the patients' medical records. The study included 314 patients from the Diabetes Clinic who expressed their informed consent to participate in the research.

Results. The study showed that diabetes is a disease which predisposes for the occurrence of depression. The occurrence of depressive symptoms of various degrees of intensity was confirmed in more than a half of the examined patients. Among the factors which exerted a significant effect on the occurrence of depressive symptoms were: diabetic neuropathy, type 2 diabetes, high BMI value, lack of occupational activity, poor material standard, and the need to obtain assistance in daily functioning due to the fact of being ill with diabetes.

Conclusions. It is necessary to implement routinely performed examinations into the diagnostic-therapeutic process to assess the state of psychological health of diabetic patients, which would allow sufficiently early application of appropriate psychological or psychiatric intervention.
\end{abstract}

\section{Key words}

diabetes, medical and socio-demographic factors, depressive disorders

\section{INTRODUCTION}

Diabetes is a civilisation disease which constitutes a serious challenge for public health. The World Health Organization (WHO) reports that the number of the population ill with diabetes worldwide has increased from 108 million in 1980 up to 422 million in 2014, and the global frequency of the occurrence of diabetes among persons aged over 18 has increased from $4.7 \%$ in 1980 up to $8.5 \%$ in 2014 . According to estimates, in 2016, as many as 1.6 million deaths were directly caused by diabetes. An increasing incidence of diabetes is mainly the problem of countries with mediocre and low income [1]. Based on data from the National Health Fund (NFZ) in Poland, it is estimated that at present more than 2 million of the population are ill with diabetes, of which about $25 \%$ are unaware of this fact. Morbidity due to diabetes is approximately $6.54 \%$ (5.81\% of males and $7.25 \%$ of females). In individuals aged over 18 this coefficient is $8 \%(7.15 \%$ of males and $8.9 \%$ of females), whereas among children aged under 15 the estimated number of persons with diabetes is 17.7 cases per 100,000 inhabitants. Prognoses predict that

Address for correspondence: Magdalena Florek-Łuszczki, Department of Medical Anthropology, Institute of Rural Health, Lublin, Poland

E-mail: magdalena.florek@wp.pl

Received: 28.01.2020; accepted: 28.02.2020; first published: 12.03.2020 in the next 15-20 years the number of diabetic patients will double in Poland [2].

One of the frequently occurring complications of diabetes is diabetic neuropathy, identified with the symptoms of dysfunction of the peripheral nervous system, after excluding many other causes of this impairment, for example, alcohol abuse, vitamin B12 deficiency associated with chronic metformine administration, demyelinating diseases or uraemia $[3,4]$. It is estimated that the risk of occurrence of neuropathy increases 10 years after the occurrence of diabetes in patients with both type 1 and 2 diabetes, and concerns $40-50 \%$ of those afflicted with this disease $[5,6,7,8,9]$. The symptoms of diabetic neuropathy experienced by patients, including sharp pain complaints, often accompanied by tingling or burning $[10,11,12]$, lead to a considerable decrease in the quality of their life. Discomfort resulting from pain sensation often leads to the limitation of performance of activities of daily living, and may also result in withdrawal from social activity, and even depressive disorders $[13,14]$.

The American Psychiatric Association Diagnostic and Statistical Manual of Mental Disorders [DSM-5] confirmed that diabetes causes mood disorders, which may result in a change in the functioning of an individual in the area of emotions, cognition and behaviour [15]. The frequency of occurrence of depression in diabetic patients may be several 
times higher, compared to the general population worldwide - approximately three times higher in patients with type 1 diabetes, and twice as high in patients with type 2 diabetes] [16]. It is estimated that depression affects approx. $20 \%$ of persons with diabetes worldwide.

The occurrence of concomitant diseases in diabetic patients is a factor which significantly deteriorates their state of psychological health. The most frequent concomitant diseases include heart diseases, arterial hypertension, dislipidaemia, neuropathy, retinopathy, diabetic foot, and renal diseases $[17,18,19,20,21]$.

Apart from biological mechanisms, the fact of contracting diabetes and depression is also associated with such factors as, among others, socio-demographic characteristics and material standard $[22,23]$.

\section{OBJECTIVE}

The aim of the study was to determine the relationship between elements of the state of health and socio-demographic characteristics of diabetic patients treated in the Diabetes Clinic at the Institute of Rural Health (IMW) in Lublin, eastern Poland, and the occurrence of depressive symptoms in these patients.

\section{MATERIALS AND METHOD}

The study was conducted among patients treated in the Diabetes Clinic at the IMW by the method of a diagnostic survey using the Beck's Depression Inventory for screening depressive symptoms, and an author-constructed questionnaire. The results obtained were correlated with the outcomes of biochemical examinations of patients, and a medical examination for the symptoms of diabetic neuropathy. The calculations were performed using IBM SPSS 25 software.

The study was conducted within the research project entitled: 'Socio-demographic conditioning of depressive disorders in patients with diabetic neuropathy' financed by the Ministry of Science and Higher Education. The project obtained a positive opinion from the Bioethics Commission at the IMW (Decision No. 6/2016).

The study was carried out in rs 2017-2019. Participation was voluntary, after the patients had given informed consent to participate, and included a total number of 314 patients in the Diabetes Clinic at the IMW.

In the presented research it was assumed that apart from biological mechanisms, personality traits, and resulting from them predispositions for the lack of coping with diabetes and its complications by the persons afflicted with the disease, demographic characteristics and social factors exert an effect on the occurrence of depressive disorders, such as, marital status, family material standard, occupational activity, presence of support or its lack, and the level of knowledge concerning the disease.

\section{RESULTS}

Socio-demographic characteristics. The social factors analyzed included: age, gender, place of residence, education and marital status, occupational status and material standard
Table 1. Demographic and social data of patients

\begin{tabular}{|c|c|c|c|}
\hline \multicolumn{2}{|c|}{ Characteristics of patients in the study } & \multirow{2}{*}{$\frac{\mathrm{N}}{190}$} & \multirow{2}{*}{$\begin{array}{c}\% \\
60.5\end{array}$} \\
\hline & Female & & \\
\hline \multirow[t]{4}{*}{ Gender } & Male & 124 & 39.5 \\
\hline & Total & 314 & 100.0 \\
\hline & $\geq 30$ years & 35 & 11.1 \\
\hline & $31-50$ & 88 & 28.0 \\
\hline \multirow[t]{4}{*}{ Age } & $51-70$ & 153 & 48.7 \\
\hline & $<70$ & 38 & 12.1 \\
\hline & Total & 314 & 100.0 \\
\hline & Urban area & 198 & 63.1 \\
\hline \multirow[t]{4}{*}{ Place of residence } & Rural area & 116 & 36.9 \\
\hline & Total & 314 & 100.0 \\
\hline & Primary & 23 & 7.3 \\
\hline & Primary vocational & 70 & 22.3 \\
\hline \multirow[t]{5}{*}{ Education } & Secondary, post-secondary & 140 & 44.6 \\
\hline & Higher & 81 & 25.8 \\
\hline & Total & 314 & 100.0 \\
\hline & Never married & 58 & 18.5 \\
\hline & Married & 180 & 57.3 \\
\hline \multirow[t]{4}{*}{ Marital status } & Widowed & 53 & 16.9 \\
\hline & Divorced/separated & 23 & 7.4 \\
\hline & Total & 314 & 100.0 \\
\hline & Occupationally active & 116 & 39.3 \\
\hline \multirow[t]{3}{*}{ Occupational status } & Occupationally inactive & 179 & 60.7 \\
\hline & Total & $295^{*}$ & 100.0 \\
\hline & Good & 78 & 24.8 \\
\hline \multirow{3}{*}{ Material standard } & Mediocre & 169 & 53.8 \\
\hline & Poor & 67 & 21.4 \\
\hline & Total & 314 & 100.0 \\
\hline
\end{tabular}

*Lack of data, not considered

(Tab.1). The majority of respondents were females (60.5\%). The patients were divided into four age groups: up to 30 years, $31-50,51-70$, and over 70 . The largest number of patients were aged $51-70$ (48.7\%). More than $63.1 \%$ of respondents were urban inhabitants, while $36.9 \%$ - rural inhabitants. The examine patients differed according to the education level. Every fourth respondent possessed higher education (25.8\%), while the reminder had post-secondary school or secondary education, and primary vocational or primary education. The majority of the examined patients were married (57.3\%), while the remainder were never married, widowed, divorced or separated. More than a half of respondents were occupationally inactive $(60.7 \%)$. The majority of patients in the study evaluated their material standard as poor or mediocre (75.2\%).

State of health. More than a half of the patients in the study had type 2 diabetes (58.3\%), while the reminder were ill with type 1 diabetes (41.7\%). The duration of the disease differed between $17.50 \pm 11.59$ years, on average, in respondents with type 1 diabetes, and $15.10 \pm 8.67$ years in patients with type 2 diabetes.

Diabetic neuropathy was observed in the majority of the examined patients (64.0\%). In addition, in the vast majority of patients participating in the study $(74.5 \%)$ there occurred micro- and macro-vascular complications related with this disease, sometimes several at a time. These were, among others, retinopathy, diabetic foot, myocardial infarction, 
stroke, arterial hypertension, and circulatory failure. Overweight or obesity was observed in as many as $76.3 \%$ of the examined patients.

The patients in the study had the level of glycosylated haemoglobin (HbAlc) determined. According to the recommendations by the Polish Diabetes Association this result for diabetic patients should remain within the range $6.1-6.5 \%$ - which is an evidence of good control of the disease. Based on these recommendations it was assumed that the HbAlc values lower than 6.1\% were below normal, the values 6.1-6.5\% - normal, and values higher than $6.5 \%$ above normal. Examinations showed that in the vast majority of the patients (90.5\%), the HbAlc value was above the upper limit of normal (Tab. 2).

Table 2. Clinical data of patients

\begin{tabular}{|c|c|c|c|}
\hline Clinical data & & $\mathrm{N}$ & $\%$ \\
\hline \multirow{3}{*}{ Type of diabetes } & Type 1 & 131 & 41.7 \\
\hline & Type 2 & 183 & 58.3 \\
\hline & Total & 314 & 100.0 \\
\hline \multirow{6}{*}{$\begin{array}{l}\text { No. of years of life with } \\
\text { diabetes }\end{array}$} & $1-5$ & 48 & 15.4 \\
\hline & $6-10$ & 62 & 19.9 \\
\hline & $11-15$ & 56 & 17.9 \\
\hline & $16-20$ & 59 & 18.9 \\
\hline & 21 or longer & 87 & 27.9 \\
\hline & Total & $312^{*}$ & 100.0 \\
\hline \multirow{3}{*}{ Neuropathy } & Neuropathy & 201 & 64.0 \\
\hline & Absence & 113 & 36.0 \\
\hline & Total & 314 & 100.0 \\
\hline \multirow{3}{*}{$\begin{array}{l}\text { Other complications of } \\
\text { diabetes (micro- and } \\
\text { macro-vascular) }\end{array}$} & Present & 234 & 74.5 \\
\hline & Absent & 80 & 25.5 \\
\hline & Total & $312^{*}$ & 100.0 \\
\hline \multirow{5}{*}{ Body Mass Index (BMI) } & $\mathrm{BMI}<18.5$ (Underweight) & 3 & 0.9 \\
\hline & $18.5 \leq \mathrm{BMI} \leq 24.9$ (Normal weight) & 71 & 22.8 \\
\hline & $25 \leq \mathrm{BMI} \leq 29.9$ (Overweight) & 74 & 23.7 \\
\hline & BMI > 30 (Obesity) & 164 & 52.6 \\
\hline & Total & $312^{*}$ & 100.0 \\
\hline \multirow{4}{*}{ Level of $\mathrm{HbA} 1 \mathrm{c}$} & $<6.1 \%$ & 19 & 6.2 \\
\hline & $6.1-6.5 \%$ & 10 & 3.3 \\
\hline & $>6.5 \%$ & 278 & 90.5 \\
\hline & Total & $307^{*}$ & 100.0 \\
\hline \multirow{5}{*}{ Beck's Inventory } & 0-11scores (no depression) & 154 & 49.0 \\
\hline & 12-19 scores (mild depression) & 84 & 26.8 \\
\hline & 20-25scores (moderate depression) & 47 & 15.0 \\
\hline & 26-63 scores(severe depression) & 29 & 9.2 \\
\hline & Total & $312^{*}$ & 100.0 \\
\hline
\end{tabular}

*Lack of data not considered

In turn, examination using the Beck's Inventory demonstrated that only less than a half of respondents (49.0\%) were free from the symptoms of depression, whereas in the remainder depression occurred of various degrees of intensity (Tab. 2).

The conditioning of the occurrence of depressive symptoms was investigated by means of logistic regression analysis (Tab. 3). The dependent variable in the model was the dichotomous variable of the occurrence of depressive symptoms (1 - No; 2 - Yes); independent variables were introduced into the model subsequently in two groups: Group 1: variables determining the selected indicators of the state of health (number of years of life with diabetes, occurrence
Table 3. Models of conditioning of occurrence of depression (results of hierarchical logistic regression by forward stepwise selection)

\begin{tabular}{llcccccc}
\hline Block & Predictor (coding) & B & SE & Wald & Df & p & I.S. \\
\hline Health & BMI & 0.028 & 0.015 & 3.592 & 1 & 0.058 & 1.029 \\
\hline & $\begin{array}{l}\text { Occurrence of } \\
\text { neuropathy }\end{array}$ & 0.456 & 0.262 & 3.035 & 1 & 0.081 & 1.577 \\
\hline $\begin{array}{l}\text { Socio- } \\
\text { demographic } \\
\text { characteristics }\end{array}$ & $\begin{array}{l}\text { Mediocre material } \\
\text { standard }\end{array}$ & - & - & 7.364 & 2 & 0.025 & - \\
\cline { 2 - 8 } & $\begin{array}{l}\text { Poor material } \\
\text { standard }\end{array}$ & 0.408 & 0.318 & 1.651 & 1 & 0.199 & 1.504 \\
\hline & $\begin{array}{l}\text { Good material } \\
\text { standard }\end{array}$ & 0.581 & 0.299 & 3.773 & 1 & 0.052 & 0.560 \\
\hline & $\begin{array}{l}\text { Occupational activity } \\
\text { Constant }\end{array}$ & -.464 & .258 & 3.233 & 1 & 0.029 & 0.628 \\
& -.201 & 0.666 & .091 & 1 & 0.763 & 0.818
\end{tabular}

Collective test of Chi-square model coefficients 20,$404 ; p<0.001$

$\mathrm{R}$ - Nagelkerke's square $=0.092$

$\mathrm{O}>\mathrm{R}>-$ odds ratio; reference category

of diabetic complications, diabetic neuropathy, BMI), and Group 2: socio-demographic characteristics (age, place of residence, marital status, education level, occupational activity, material standard).

Analysis of logistic regression for the model of conditioning of the occurrence of depression revealed four variables, which significantly affected the probability of occurrence of this disease - the respondents' material standard, their occupational activity, BMI, and the occurrence of neuropathy.

The occurrence of depressive symptoms in diabetic patients is significantly related with the development of diabetic neuropathy. The occurrence of neuropathy increases the risk of depression by $57.7 \%$ (Tab. 3). Also, the risk of development of depressive symptoms increases together with the value of the Body Mass Index. An increase of this index by one unit results in an increase in the risk of depression by $2.9 \%$, which means that an increase in the BMI by 10 units increases the risk by $29 \%$. Therefore, it should be adopted that overweight and obesity are the risk factors of depressive symptoms.

While introducing the variable into the model - the respondents' material standard, it was assumed that the reference category for 'material standard' is its assessment as mediocre. The possession of a poor material standard, compared to mediocre, results in an increase in the probability of the occurrence of depression by $50.4 \%(\mathrm{O} . \mathrm{R}=1.504)$. The effect of a good material standard is the opposite which, compared to the mediocre, reduces the risk of the occurrence of depressive symptoms by $44.0 \%$. Also, the probability of the occurrence of depressive symptoms significantly decreases (by $37.2 \%$ ) in occupationally active persons (O.R.= 0.628).

While seeking statistically significant relationships between the occurrence of the symptoms of depressive disorders, and clinically confirmed elements of the state of health of patients and socio-demographic characteristics which were not considered in logistic regression analysis, statistical analyses were performed using Pearson's chisquare test. Analyses performed based on the data obtained in the study demonstrated that the occurrence of depressive symptoms was not statistically significantly related with such parameters of the state of health as: the level of glycosylated haemoglobin (HbAlc) and occurrence of micro- and macrovascular complications. However, such a relationship was noted considering the type of diabetes. Depressive symptoms were significantly more often observed $\left(\mathrm{chi}^{2}=11.23\right.$; $\mathrm{df}=3$; 
$\mathrm{p}=0.011)$ among patients with type 2 diabetes $(57.4 \%)$, compared to those with type 1 diabetes (43\%) (Fig. 1). In turn, among non-health factors, a significant effect of which was observed in statistical analysis, was reported by the examined patients, the need for obtaining assistance in daily living functioning due to being ill with diabetes (Fig. 1).

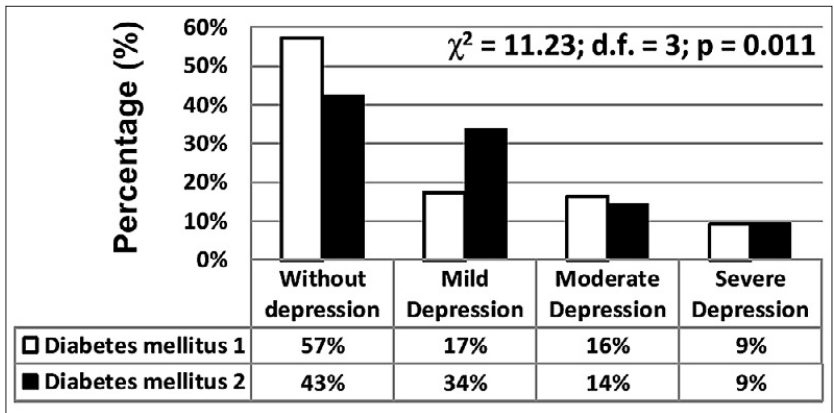

Figure 1. Type of diabetes and occurrence of depression

In patients who needed support in performing activities of daily living, such as housework, shopping, washing and getting dressing, the measurement of insulin and construction of a diet, the occurrence of moderate or severe depression, was observed significantly more frequently $\left(\mathrm{chi}^{2}=16.035 ; \mathrm{df}=3\right.$; $\mathrm{p}=0.014$ ), compared to those who did not report the need for assistance. In turn, mild depression was significantly more often noted in patients who did not require assistance (Fig. 2).

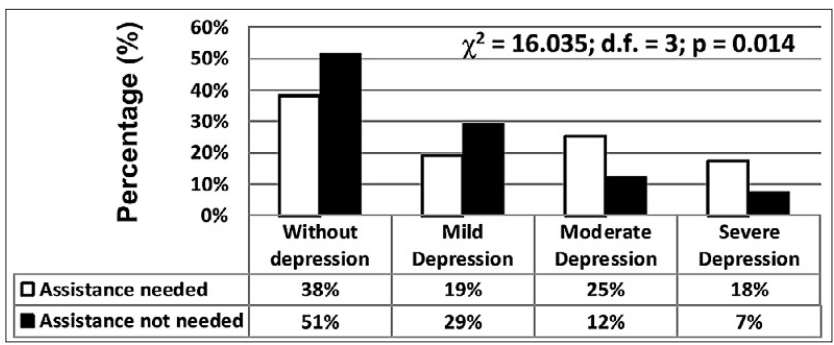

Figure 2. Need for assistance due to the disease and occurrence of depression.

\section{DISCUSSION}

In studies by other researchers, the percentages of diabetic patients diagnosed with depression based on the tests performed were slightly lower. An international study by researchers from San Ignacio's Hospital in Bogotá, Colombia, conducted over approx. 10 years (International Diabetes Management Practices Survey - IDMPS), within which data were analyzed collected among nearly 9,900 patients with diabetes from 21 countries worldwide, demonstrated that almost $31 \%$ of patients with type 1 diabetes and $29 \%$ of those with type 2 diabetes showed the symptoms of mild to severe depression [24]. In turn, a study carried out among Mexican patients indicated that the problem of depression concerned $48.2 \%$ of patients with type 2 diabetes [25].

The results of the presented study demonstrate that the occurrence of depressive disorders as a consequence of diabetes was a considerable problem in the group of examined patients. In the examination using the Beck's Inventory as many as $51 \%$ obtained a result confirming depressive symptoms of varying intensity. Depression was significantly more often observed in patients with type 2 diabetes, compared to those with type 1 diabetes $(57.4 \%$ vs. $43.0 \%)$. This high percentage of persons with depressive symptoms among patients with type 2 diabetes may be due to the fact that this disease is diagnosed considerably later, compared to type 1 diabetes, and consequently, 'becoming familiar' with the disease and the necessity for changing the mode and style of life is the factor which, especially at an early phase, may cause depressed mood states and depression. There is also a possibility that depression was primary to the diagnosis of type 2 diabetes diagnosed. For example, meta-analysis, the aim of which was assessment of the relationship between depression and diabetes, confirmed that the risk of diabetes is by $37 \%$ higher in persons with depressive disorders, than in the healthy population [26]. Another study also demonstrated that depression is an independent risk factor of type 2 diabetes $[27,28]$.

The results of own study showed that an improper BMI value and the occurrence of diabetic neuropathy confirmed by medical examination are among factors exerting a significant effect on the occurrence of depression in diabetic patients. A similar relationship has been confirmed in studies by other researchers [29, 30, 31, 32, 33]. However, in the presented study, the level of increase in the risk of occurrence of depression was estimated. Analyses confirmed that neuropathy increases this risk by $57.7 \%$, and an increase in the BMI value by 1 unit increases the risk of the occurrence of depression by $2.9 \%$. Apart from factors directly associated with the state of health of the examined patients in relation with depression, the presented study demonstrated that factors of socio-economic character also belong to this group. Among these factors, material standard, occupational activity and support on the part of close persons occupy a special position. Investigations using logistic regression analysis confirm that good material standard and being occupationally active have a protective effect (decrease the risk) in the context of occurrence of depression in persons ill with diabetes.

In turn, significant differences in the occurrence or absence of depression are noted according to the necessity of using support in the performance of activities of daily living. Own study confirmed that being dependent on other family members significantly increased the risk of development of depression. Such persons frequently felt dissatisfied with their lives, abandon many of the activities and interests previously carried out, and experience emptiness in their lives. For these persons, diabetes and its consequences are a considerable psycho-social burden.

The presence of depression and anxiety in diabetic patients deteriorates prognoses in this disease, increases the probability of occurrence in these patients of improper behaviours related with the process of treatment which, in consequence, leads to a considerable reduction in the quality of their lives [34, 35] and an increase in mortality $[36,37]$.

\section{CONCLUSIONS}

1. Depressive symptoms of varying intensity were observed in slightly more than a half of the examined diabetic patients. 2. Among the factors which to the greatest degree increased the risk of depression among these patients were: diabetic neuropathy, type 2 diabetes, high BMI value, lack of occupational activity, poor material standard, and the 
need for obtaining assistance in daily functioning due to the fact of being ill with diabetes.

3. The results of the study obtained indicate the necessity for introducing into the diagnostic-therapeutic process routine examinations assessing the state of psychological health of diabetic patients, which would allow an early appropriate psychological or psychiatric intervention.

\section{REFERENCES}

1. https://www.who.int/news-room/fact-sheets/detail/diabetes [access date: 29.11 .2019$]$.

2. (http://www.nfz.gov.pl/nfz-blizej-pacjenta/cukrzyca/ [access date: 29.08.2019].

3. Boulton AJM, Vinik AI, Arezzo JC, Bril V, Feldman EL, Freeman R, et al. Diabetic neuropathies: A statement by the American Diabetes Association. Diabetes Care. 2005; 28: 956-962.

4. Boulton AJM, Malik RA, Arezzo JC, Sosenko JM. Diabetic somatic neuropathies. Diabetes Care. 2004; 27: 1458-1486.

5. Dyck PJ, Kratz KM, Karnes JL, et al. The prevalence by staged severity of various types of diabetic neuropathy, retinopathy, and nephropathy in a population-based cohort: The Rochester diabetic neuropathy study. Neurology. 1993; 43: 817-824.

6. Martin CL, Albers JW, Pop-Busui R, et al. Neuropathy and related findings in the diabetes control and complications trial/epidemiology of diabetes interventions and complications study. Diabetes Care. 2014; 37: 31- 38 .

7. Pop-Busui R, Lu J, Brooks MM, et al. Impact of glycemic control strategies on the progression of diabetic peripheral neuropathy in the bypass angioplasty revascularization investigation 2 diabetes (BARI 2D) cohort. Diabetes Care. 2013; 36: 3208-3215.

8. Ismail-Beigi F, Craven T, Banerji MA, et al. Effect of intensive treatment of hyperglycaemia on microvascular outcomes in type 2 diabetes: An analysis of the ACCORD randomised trial. Lancet. 2010; 376: 419-430.

9. Ang L, Jaiswal M, Martin C, et al. Glucose control and diabetic neuropathy: Lessons from recent large clinical trials. Curr Diab Rep. 2014; 14: 1-15.

10. Schreiber AK, Nones CFN, Reis RC, Chichorro JG, Cunha JM, Diabetic neuropathic pain: Physiopathology and treatment. World J Diabetes. 2015; 6: 432-444.

11. Bansal V, Kalita J, Misra UK. Diabetic neuropathy. Postgrad Med J. 2006; 82: 95-100.

12. Tesfaye S, Boulton AJ, Dickenson AH. Mechanisms and management of diabetic painful distal symmetrical polyneuropathy. Diabetes Care. 2013; 36: 2456-2465.

13. Quattrini C, Tesfaye S. Understanding the impact of painful diabetic neuropathy. Diabetes Metab Res Rev. 2003; 19 Suppl 1: 2-8.

14. Gore M, Brandenburg NA, Dukes E, Hoffman DL, Tai KS, Stacey B. Pain severity in diabetic peripheral neuropathy is associated with patient functioning, symptom levels of anxiety and depression, and sleep. J Pain Symptom Manage. 2005; 30: 374-385.

15. American Psychiatric Association, Task F. Diagnostic and statistical manual of mental disorders DSM-5. Fifth edition 2013.

16. Roy T, Lloyd CE. Epidemiology of depression and diabetes: a systematic review. J Affect Disord. 2012; 142 (Suppl): S8-S21.

17. Ahmad A, Abujbara M, Jaddou H, Younes NA, Ajlouni K. Anxiety and depression among adult patients with diabetic foot: prevalence and associated factors. J Clin Med Res. 2018; 10: 411-418.

18. Abdulghani HM, AlRajeh AS, AlSalman BH, et al. Prevalence of diabetic comorbidities and knowledge and practices of foot care among diabetic patients: a cross-sectional study. Diabetes Metab Syndr Obes. 2018; 11; 417-425.

19. Wierzba W, Karnafel W, Tyszko P, Kanecki K, Śliwczyński A. Assessment of the incidence rate of end-stage renal disease in patients with and without diabetes in Poland. Ann Agric Environ Med. 2018; 25: $568-571$.

20. Kvan E, Pettersen KI, Aasmund LS. High mortality in diabetic patients with acute myocardial infarction: Cardiovascular co-morbidities contribute most to the high risk. Int J Cardiol. 2007; 121: 84-88.

21. Jelinek HF, Osman WO, Khandoker AH, Khalaf K, Lee S, Almahmeed W, Alsafar HS. Clinical profiles, comorbidities and complications of type 2 diabetes mellitus in patients from United Arab Emirates. BMJ Open Diab Res Care. 2017;5:e000427. doi:10.1136/bmjdrc-2017-000427. 22. Agardh E, Allebeck P, Hallqvist J, Moradi T, Sidorchuk A. Type 2 diabetes incidence and socio-economic position: a systematic review and meta-analysis. Int J Epidemiol. 2011; 40: 804-818.

23. Folb N, Lund C, Fairall LR, Timmerman V, Levitt NS, Steyn K, Bachmann MO. Socioeconomic predictors and consequences of depression among primary care attenders with non-communicable diseases in the Western Cape, South Africa: cohort study within a randomised trial. BMC Public Health. 2015; 15: 1194.

24. http://www.idmps.org/infographics/index.html [access date: 20.12.2019]

25. Tovilla-Za'rate C, Jua'rez-Rojop I, Jimenez YP, et al. Prevalence of anxiety and depression among outpatients with type 2 diabetes in the Mexican population. PLoS One 2012; 7(5): e36887. doi:10.1371/ journal.pone.0036887

26. Carnethon MR, Biggs ML, Barzilay JI, et al. Longitudinal association between depressive symptoms and incident type 2 diabetes mellitus in older adults: the Cardiovascular Health Study. Arch Intern Med. 2007; 167: 802-807.

27. Musselman DL, Betan E, Larsen H, Phillips LS. Relationship of depression to diabetes types 1 and 2: epidemiology, biology and treatment. Biol. Psychiatry 2003; 54: 317-329.

28. Eaton WW, Armenian H, Gallo J, et al. Depression and risk for onset of type II diabetes: a prospective population-based study. Diabetes Care. 1996; 19: 1097-1102.

29. Sharif S, Raza MT, Mushtaq S, Afreen B, Hashmi BA, Ali MH. Frequency of depression in patients with type 2 diabetes mellitus and its relationship with glycemic control and diabetic microvascular complications. Cureus 2019; 11: e5145. doi: 10.7759/cureus.5145.

30. Katon W, Von Korff M, Ciechanowski P, Russo J, Lin E, Simon G, et al. Behavioral and clinical factors associated with depression among individuals with diabetes. Diabetes Care. 2004; 27: 914-920.

31. de Groot M, Anderson R, Freedland KE, Clouse RE, Lustman PJ. Association of depression and diabetes complications: a meta-analysis. Psychosom Med. 2001; 63: 619- 630.

32. Gendelman N, Snell-Bergeon JK, McFann K, et al. Prevalence and correlates of depression in individuals with and without type 1 diabetes. Diabetes Care. 2009; 32: 575-579.

33. D’Amato C, Morganti R, Greco C, et al. Diabetic peripheral neuropathic pain is a stronger predictor of depression than other diabetic complications and comorbidities. Diab Vasc Dis Res. 2016; 13: 418-428.

34. Gonzalez JS, Peyrot M, McCarl LA, Collins EM, Serpa L, Mimiaga MJ, Safren SA. Depression and diabetes treatment nonadherence: a meta-analysis. Diabetes Care. 2008; 31: 2398-2403.

35. Baumeister H, Hutter N, Bengel J, Harter M. Quality of life in medically ill persons with comorbid mental disorders: a systematic review and meta-analysis. Psychother Psychosom. 2011; 80: 275-286.

36. Egede LE, Nietert PJ, Zheng D. Depression and all-cause and coronary heart disease mortality among adults with and without diabetes. Diabetes Care. 2005; 28: 1339-1345.

37. Hofmann M, Kohler B, Leichsenring F, Kruse J. Depression as a risk factor for mortality in individuals with diabetes: a meta-analysis of prospective studies. PLoS One. 2013; 8(11): e79809. 